\title{
Performance of a fungal monolith bioreactor for the removal of styrene from polluted air
}

\author{
Eldon R. Rene, M. Estefania López, María C. Veiga, Christian Kennes
}

Bioresource Techonolgye, volume 101 issue 8, April 2010, Pages 2608 to 2615

DOI: 10.1016/j.biortech.2009.10.060

\section{Abstract}

Gas-phase styrene removal using the fungus, Sporothrix variecibatus was evaluated in a novel monolith bioreactor, receiving a continuous supply of nutrients from the trickling liquid phase. During the start-up process, the monolith reactor was operated for 22 days with relatively low styrene concentrations in the gas-phase $\left(<0.4 \mathrm{~g} \mathrm{~m}^{-3}\right)$. Afterwards, continuous experiments were carried out at different inlet styrene concentrations, ranging between 0.06 and $2.5 \mathrm{~g} \mathrm{~m}^{-3}$, and at two different flow rates corresponding to empty bed residence times (EBRTs) of 77 and $19 \mathrm{~s}$, respectively. A maximum elimination capacity of $67.4 \mathrm{~g} \mathrm{~m}^{-3} \mathrm{~h}^{-1}$ was observed at an inlet styrene load of $73.5 \mathrm{~g} \mathrm{~m}^{-3} \mathrm{~h}^{-1}$. However, it was observed that the critical loading rates to the monolith bioreactor were a strong function of the gas residence time. The critical load, with greater than $95 \%$ styrene removal was $74 \mathrm{~g} \mathrm{~m}^{-3} \mathrm{~h}^{-1}$ at an EBRT of $77 \mathrm{~s}$, while it was only $37.2 \mathrm{~g} \mathrm{~m}^{-3} \mathrm{~h}^{-1}$ for an EBRT of $19 \mathrm{~s}$. After 92 days of continuous operation, due to excess biomass growth on the surface of the monolith, the biodegradation efficiency decreased significantly. To ascertain the instantaneous response of the attached fungus, to withstand fluctuations in loading conditions, two dynamic shock loads were conducted, at EBRTs of 77 and 19 s, respectively. It was observed that, the performance of the monolith bioreactor decreased significantly at low residence times, when subjected to high shock loads. The recovery times for high performance, in both cases, did not exceed more than $1 \mathrm{~h}$.

\section{Keywords}

Monolith reactor; Sporothrix variecibatus; Biofilter; Clogging; Transient-state operation 


\section{Introduction}

At relatively low pollutant concentrations $\left(<5 \mathrm{~g} \mathrm{~m}^{-3}\right)$, biofiltration is one of the most cost-effective and efficient means to remove volatile organic compounds (VOCs) and other hazardous air pollutants (HAPs) emanating from chemical process vent streams, prior to their discharge into the ambient environment. The removal of styrene vapours, amongst others, emitted from various chemical process industries such as plastic moulding, fibre-glass, pipes and automobile component manufacture industries, is very important to meet pollution standards. Styrene is an important organic chemical classified as a VOC under Title III of the Clean Air Act Amendments of 1990, proposed by the US - EPA. It has an odour threshold of $0.43 \mathrm{mg} \mathrm{m}^{-3}$ and a saturation constant of $25.6 \mathrm{~g} \mathrm{~cm}^{-3}$ in air at $20^{\circ} \mathrm{C}$ (James and Castor, 2000). Biological treatment systems such as biofilters (BF) and biotrickling filters (BTF) have proved to be efficient in handling styrene vapours, at different inlet loading rates (ILR), in lab-scale conditions (Rene et al., 2009a). In the last few years, several conventional and innovative reactor configurations have been tested, offering effective biodegradation of a wide range of organic and inorganic gas-phase pollutants of environmental significance (Kennes and Thalasso, 1998, Kennes and Veiga, 2001 and Kennes et al., 2009). Recently, the pursuance among researchers to examine different packing materials as support matrix for biomass growth in bioreactors applied to waste gas treatment has increased exponentially. This has led to provide new insights into the physico-chemical and biological factors affecting performance of different bioreactor configurations. Under this line of progressive research, our laboratory has undertaken a few initiatives for the development of new reactor systems to treat hydrophilic and hydrophobic VOCs using a novel monolith reactor (Jin et al., 2006a and Jin et al., 2008).

A monolith reactor is a reactor in which the biomass is attached on a ceramic, plastic or metal structure with uniform parallel channels separated by thin walls. The operating mode depends on the size of the straight parallel channels. In large channels, the fluid trickles downwards along the channel walls and the gas travels co-currently or countercurrently through the channel in the core. In smaller channels, the dominant flow pattern is a segmented slug flow or bubble train flow of elongated bubbles and slugs, commonly referred to as Taylor flow in the literature (Kreutzer et al., 2005 and Jin et al., 2006a). Theoretically, the gas and liquid would ideally follow near plug flow conditions as they travel with uniform velocities, as separated packages within a monolith channel. The wall is wetted by a thin liquid film, while the gas pollutant is easily transported through the film allowing higher mass transfer rates. The biocatalytically active biofilm layer remains at the wall when the liquid slug passes by. Inside the liquid slug itself, a re-circulation pattern is observed. This re-circulation enhances transfer of gas from the caps of the bubble to the biocatalyst with higher removal by the attached biomass. In environmental applications, the monolith reactor is widely used as medium for non-biological catalyst support such as the cleaning of automobile exhaust gases and industrial off gases due to the following advantages: (i) simple reactor configuration and energy efficient operation due to low pressure drop, (ii) high external surface area and high mechanical strength, (iii) high interfacial mass transfer rates, (iv) better liquid distribution at low liquid flow rates, and (v) scaling up promises to be relatively easy compared to other reactor types. However, a continuous supply of nutritive aqueous phase is a pre-requisite for optimal bioreactor performance with inert support materials such as ceramic structures. These nutrients, are not naturally 
available in inert filter beds, and the aqueous nutrient solution acts as a main agent for oxygen and substrate transport from the gas to the biofilm.

Extensive studies on the removal of VOCs, belonging to the group of non-oxygenated aromatic pollutants like styrene, by filamentous fungi and yeast like fungi were initiated only very recently (Kennes and Veiga, 2004). Experiments with new fungal isolates were also done with toluene, appearing to be another easily biodegradable alkylbenzene in fungi (Woertz et al., 2001 and Estévez et al., 2005). The main advantage of formenting fungal rather than bacterial growth for biodegradation of hydrophobic pollutants is their ability to degrade the substrates at extreme environmental conditions regardless of the $\mathrm{pH}$ fluctuations, low water content and limiting nutrient concentrations. In a recent study conducted in our laboratory, styrene removal from waste gases was studied in a perlite biofilter inoculated with petrochemical wastewater sludge and, a white coloured yeast like thermally dimorphic fungus, Sporothrix variecibatus, that utilizes styrene as sole carbon and energy source was isolated.

The monolith bioreactor has recently been tested successfully for the removal of both hydrophilic and hydrophobic VOCs from waste gases (Jin et al., 2006a, Jin et al., 2008 and Fang and Govind, 2007). Jin et al. (2008) used a yeast-dominant enriched culture, which could tolerate low- $\mathrm{pH}$, to inoculate a monolith reactor for treating methanol polluted air. More than $80 \%$ removal, for methanol loads greater than $250 \mathrm{~g} \mathrm{~m}^{-3} \mathrm{~h}^{-1}$, suggests the extent of mineralization possible for hydrophilic VOCs in such a monolith reactor, at a load that is often not treatable in BF and BTF at such low$\mathrm{pH}$. Fang and Govind (2007) tested an activated carbon coated monolith reactor having porous channel walls, made of porous cordierite to support biomass, under diffusive and convective flow conditions to treat gas-phase toluene at low concentrations. High removal during the first two weeks of operation was attributed to adsorption of toluene by activated carbon on the monolith and the difference in removal efficiencies were a result of the different flow pattern inside the monolith modules. Though the maximum EC were low in both the flow types, the convective flow type gave higher EC $\left(7 \mathrm{~g} \mathrm{~m}^{-3} \mathrm{~h}^{-1}\right)$ than the diffusive flow type configuration $\left(3 \mathrm{~g} \mathrm{~m}^{-3} \mathrm{~h}^{-1}\right)$.

In this paper, we focus on the removal of a more hydrophobic VOC, styrene, in the concentration range of $0.06-2.5 \mathrm{~g} \mathrm{~m}^{-3}$ in a fungal monolith bioreactor under steady-state and transient conditions. This is the first paper of its kind to report on the use of fungal biocatalyst in such system and on transient-state effects in monolith bioreactors for waste gas treatment, a test more often investigated in lab-scale conditions in BF, BTF and continuous stirred tank bioreactors (CSTB).

\section{Methods}

\subsection{Microbial inoculation and medium composition}

Sporothrix variecibatus, isolated from a previously operated biofilter treating styrene vapours was used for inoculating the monolith reactor. The pure culture was maintained on $15 \mathrm{~g}$ agar $\mathrm{L}^{-1}$, in a petri dish, and prepared with a well-defined mineral salt medium having the following composition (per liter in distilled water): $0.5 \mathrm{~g} \mathrm{~K}_{2} \mathrm{HPO}_{4}$, $0.1 \mathrm{~g}$ $\mathrm{MgSO}_{4} \cdot 7 \mathrm{H}_{2} \mathrm{O}, 4.5 \mathrm{~g} \mathrm{K \textrm {K } _ { 2 }} \mathrm{PO}_{4}, 2 \mathrm{~g} \mathrm{NH} 4 \mathrm{Cl}$, and $2 \mathrm{~mL}$ vitamins and trace minerals ( Kennes et al., 1996). The culture medium was autoclaved at $120^{\circ} \mathrm{C}$ for 20 min before adding the filter-sterilized solutions of vitamins and trace minerals. Oxyacetylene ( $1 \mathrm{~g}$ ) 
was aseptically added to $1 \mathrm{~L}$ of sterilized agar medium to prevent the growth of any bacterial colony. The petri dish containing the agar and styrene utilizing fungus were incubated in a dessicator at ambient conditions, in the presence of styrene vapours, supplied as the carbon source for fungal growth. The original $\mathrm{pH}$ of the medium was 5.9 .

Before inoculation in the monolith reactor, the enrichment culture was grown in $1 \mathrm{~L}$ erlenmeyer flasks (working volume - $250 \mathrm{~mL}$ ) on styrene, having an initial concentration of about $50 \mathrm{mg} \mathrm{L}^{-1}$ at $30^{\circ} \mathrm{C}$ and at constant shaking at $175 \mathrm{rpm}$. After 48-56 h of growth, having reached an optical density (OD) of 0.9 at $600 \mathrm{~nm}$, the cells were harvested by centrifugation at $5000 \mathrm{rpm}$ for $20 \mathrm{~min}$ and re-suspended in $2 \mathrm{~L}$ fresh nutrient medium to be used as inoculum for the continuous monolith bioreactor. After homogenizing, these cultures were stored in a reservoir tank, so as to re-circulate it over the top of the monolith reactor.

\subsection{Monolith reactor}

The ceramic monolith was supplied by Rauschert Verfahrenstechnik GmbH (Germany). The experimental setup used in the current work is shown in Fig. 1. The monolith packing has the following characteristics; geometry-square vertical channel ducts, length $-15 \mathrm{~cm}$, cross-section $-10 \times 10 \mathrm{~cm}$, number of channels $-26 \times 26$, channel width $-0.3 \mathrm{~cm}$, density $-850 \mathrm{~kg} \mathrm{~m}^{-3}$, geometric surface area $-800 \mathrm{~m}^{2} \mathrm{~m}^{-3}$, void fraction $-64 \%$. The monolith block was housed in a Plexiglas column of thickness $1 \mathrm{~cm}$, having the following dimensions $(1 \times b \times h)-13 \times 13 \times 36 \mathrm{~cm}$. The monolith block was placed at a height of $5 \mathrm{~cm}$ from the bottom, held with extended Plexiglas support, and positioned firmly with Teflon padding. Silicone glue was applied on the gap between the monolith block and Plexiglas wall surface, to prevent any flow of pollutant and re-circulation liquid, which could otherwise lead to bypassing of both the phases. Nutrient medium, also containing suspended pure cultures of $S$. variecibatus was pumped from the feed tank placed at the bottom of the setup through a peristaltic pump (model 323E/D, Watson-Marlow Limited, Falmouth Cornwall, England) into the distribution manifold, a perforated Petri dish. Initially, during the inoculation step, the media was well-mixed using a magnetic stirrer (Stuart ${ }^{\circledR}$ Model-CB161) for 3 days. After the inoculation step, the distributor was replaced by a sprinkler type distributor that could operate only under pressure. Hence, once visible biomass was noticed on the surface of the monolith, medium in the feed tank was replaced by fresh medium and recirculated without stirring to allow settling of suspended solids. This was done to prevent clogging of the sprinkler, which would have been blocked by biomass otherwise. This also enabled to periodically remove the sloughed off biomass from the monolith. The sprinkler type distributor was placed $5 \mathrm{~cm}$ from the top section of the housing. Both the liquid medium and the incoming air, used to control the empty bed residence time (EBRT) of pollutant, was mixed at a T-intersection provided before the sprinkler, outside the housing unit. This created the extra pressure required to activate the sprinkler and to spray the media almost uniformly over the square-cross-sectional surface of the monolith. Passing the nutrient medium by mixing with the incoming air also increased the liquid trickling rate within the monolith channels. Additionally, the top section of the monolith reactor, having a void dimension, $(1 \times b \times h)$ $15 \times 15 \times 15 \mathrm{~cm}$, acted as a mixing chamber, where styrene vapours generated at low flow rate from a styrene reservoir was well-mixed before passing through the monolith channels supporting the active culture of $S$. variecibatus. 


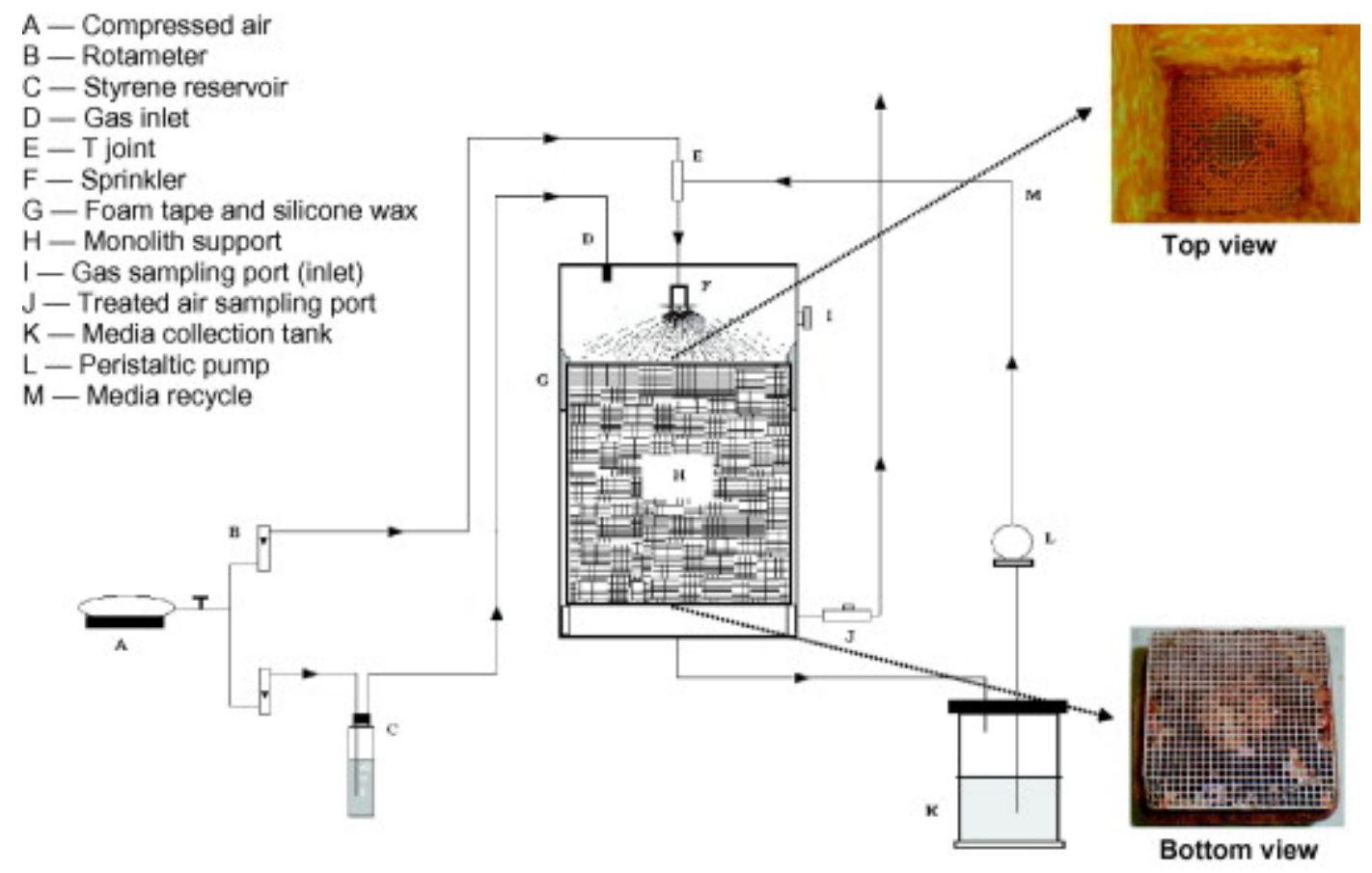

Fig. 1.

Schematic of the monolith bioreactor for waste gas treatment and photographs showing biomass growth on the straight narrow channels of monolith bioreactor (top view-shows clogging with mat-like biomass on wall surface and zones with no biomass, bottom view-shows uneven biomass growth).

Gas-phase styrene concentrations were varied from $0.06-2.5 \mathrm{~g} \mathrm{~m}^{-3}$ by changing the flow rate of the different gas streams. The monolith bioreactor was operated in a cocurrent flow mode. The flow rate of the trickling liquid was kept constant at $50 \mathrm{~mL} \mathrm{~min}{ }^{-1}$. The height of the distributor from the top of the housing unit is an important factor in achieving uniform phase distribution. In this case, an attempt was made to adjust the height by placing it at different levels $(5-10 \mathrm{~cm})$ within the top section of the experimental setup. Nevertheless, the distribution zone remained the same and it was observed that, the lowest the distance from the surface of the monolith channel, the faster was the rate of biomass sloughing from the surface. Hence as explained earlier, it was decided to carry out experiments by placing the sprinkler at a height of $10 \mathrm{~cm}$ from the monolith surface. This caused sprinkling of medium on the wall surface, which resulted in some mat-like growth of $S$. variecibatus.

\subsection{Measurements and analytical methods}

The pressure drop across the monolith was measured using a differential U-tube water manometer connected to the top and bottom section of the housing, with the operational range of $0-40 \mathrm{~cm} \mathrm{H}_{2} \mathrm{O}$. These pressure drop values were then normalized per meter monolith packing height. A Crison model $507 \mathrm{pH}$ meter, connected to an Ingold electrode was used for measuring the $\mathrm{pH}$. Biomass weight was estimated by measuring the OD, and a standard calibration line was plotted based on the relationship between dry weight and OD. The absorbance $(\lambda=600 \mathrm{~nm})$ of the liquid cultures, corresponding 
to the growth of $S$. variecibatus with styrene as the carbon source, was measured by using a UV-Vis spectrophotometer (Hitachi, Model U-200, Pacisa and Giralt, Madrid, Spain). Gas samples collected from sampling ports, before and after the monolith packing, were subjected to chromatographic analysis, on a HP 5890 gas chromatograph, using a $50 \mathrm{~m}$ TRACER column and a FID. The flow rates were $30 \mathrm{ml} \mathrm{min}^{-1}$ for $\mathrm{H}_{2}$ and $300 \mathrm{ml} \mathrm{min}^{-1}$ for air. Helium was used as the carrier gas at a flow rate of $2 \mathrm{ml} \mathrm{min}^{-1}$. The temperatures at the GC injection, oven and detection ports were 250, 120 and $250{ }^{\circ} \mathrm{C}$, respectively. $\mathrm{CO}_{2}$ was analyzed with a $\mathrm{HP} 5890$ gas chromatograph equipped with a TCD. The injection and oven temperatures were 90 and $25^{\circ} \mathrm{C}$, respectively, with the TCD set at $100{ }^{\circ} \mathrm{C}$.

The top section of the monolith housing unit had an open/close type Plexiglas lid, lined with air proof gaskets. This permitted to take a few pictures showing biomass growth on the top surface of the monolith. A picture of the bottom surface was taken after the completion of all experiments, nearly after 120 days reactor operation.

\section{Results and discussions}

\subsection{Monolith bioreactor start-up}

Empty bed residence time (EBRT), a critical factor affecting bioreactor performance was calculated as follows,

$$
\tau=\frac{V}{Q} \times 3600, \mathrm{~s}_{\tau=\mathrm{VQ} \times 3600, \mathrm{~s}}
$$

where $\tau$, is the EBRT in seconds, $V$ is the total monolith reactor volume, $\mathrm{m}^{3}$, and $Q$ is the volumetric gas-flow rate, $\mathrm{m}^{3} \mathrm{~h}^{-1}$. After inoculating the monolith reactor with pure cultures of Sporothrix sp., the reactor was fed with low concentrations of styrene (0.07$0.43 \mathrm{~g} \mathrm{~m}^{-3}$ ) and a low air flow rate of $0.07 \mathrm{~m}^{3} \mathrm{~h}^{-1}$, corresponding to an EBRT of $77 \mathrm{~s}$. During the first 5 days, the removal efficiency (RE) was less than 20\%, though visible biomass growth was seen on the surface of the monolith from the first day. A gradual increase in the RE was observed, from nearly $40 \%$ on the 8th day, reaching about $90 \%$ on the 17th day, and almost $100 \%$ in the next few days ( Fig. 2). During the 22 days of start-up period, the styrene loading rates were less than $10 \mathrm{~g} \mathrm{~m}^{-3} \mathrm{~h}^{-1}$, and pressure drop values were less than $0.4 \mathrm{~cm} \mathrm{H}_{2} \mathrm{O} / \mathrm{m}$ bed height. 


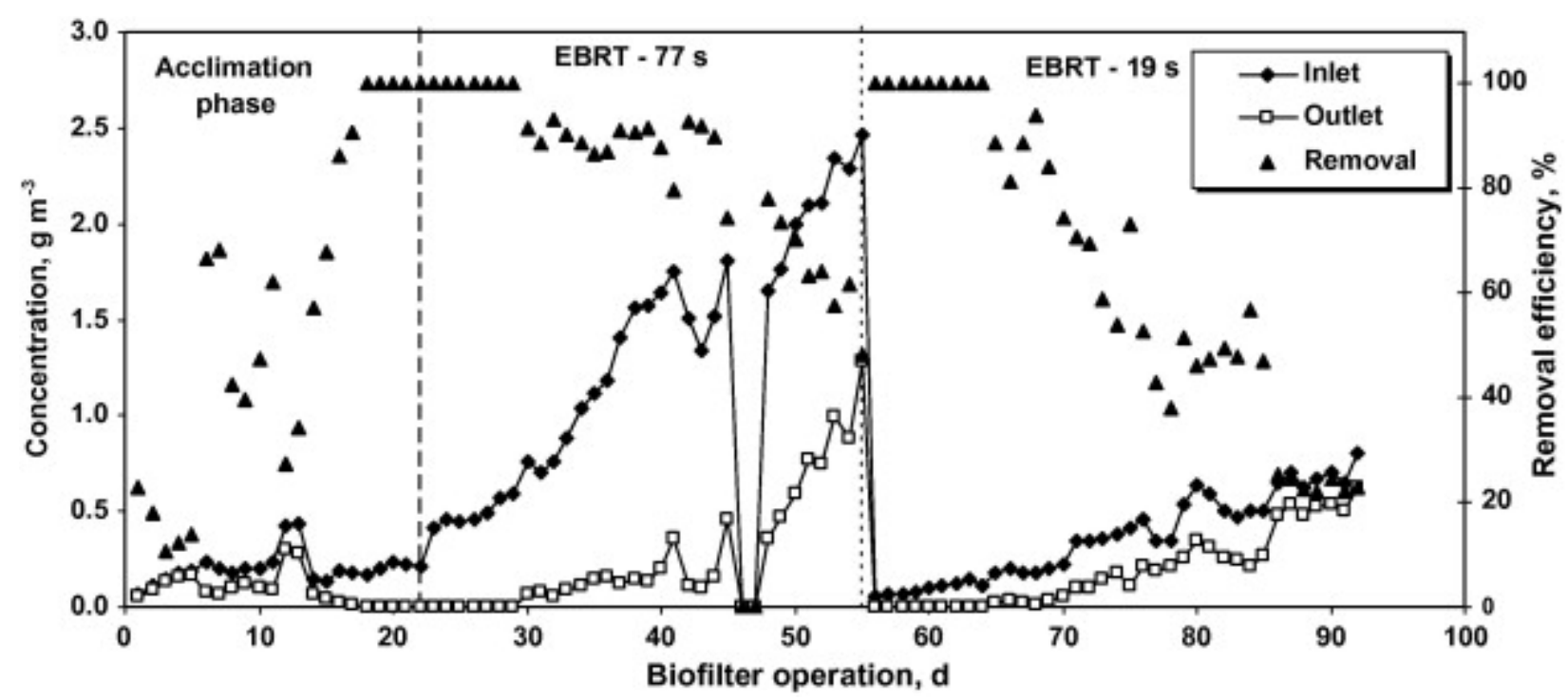

Fig. 2.

Concentration and removal efficiency profiles during continuous operation.

\subsection{Influence of styrene concentration and EBRT on the removal efficiency}

For better understanding of the styrene elimination rate, after acclimation, experiments were carried out in two phases, at an EBRT of 77 and $19 \mathrm{~s}$ and at concentrations ranging from 0.06 to $2.5 \mathrm{~g} \mathrm{~m}^{-3}$, as illustrated in Fig. 2. In these two phases, the minimum and maximum styrene loading rates to the bioreactor were 19.1 and $115.1 \mathrm{~g} \mathrm{~m}^{-3} \mathrm{~h}^{-1}$ (EBRT of $77 \mathrm{~s}$ ) and 10.8 and $150.9 \mathrm{~g} \mathrm{~m}^{-3} \mathrm{~h}^{-1}$ (EBRT of $19 \mathrm{~s}$ ), respectively. As evident from Fig. 2, once steady-state removal profiles were attained on the 22nd day, the concentration was linearly increased from about $0.4-1.64 \mathrm{~g} \mathrm{~m}^{-3}$ to envisage the maximum attainable EC under this condition. For concentrations up to $0.8 \mathrm{~g} \mathrm{~m}^{-3}$, and at an EBRT of $77 \mathrm{~s}$, corresponding to an ILR of $76.7 \mathrm{~g} \mathrm{~m}^{-3} \mathrm{~h}^{-1}$, more than $90 \%$ of the incoming styrene vapour was removed. However, the increase in loading rate also enhanced biomass growth within the narrow channels of the monolith. This was reflected by an increase in the pressure drop values from nearly $1.2 \mathrm{~cm} \mathrm{H}_{2} \mathrm{O}$ on the $31 \mathrm{st}$ day, to about $6.8 \mathrm{~cm} \mathrm{H}_{2} \mathrm{O}$ on the 41st day (Fig. 3). On the 45th day, pressure drop values further increased to $7.2 \mathrm{~cm} \mathrm{H}_{2} \mathrm{O}$, and the $\mathrm{RE}$ dropped to $74.5 \%$ at an ILR of $84.5 \mathrm{~g} \mathrm{~m}^{-3} \mathrm{~h}^{-1}$. The monolith reactor was stopped (days 46 and 47) for maintenance, by cutting off the feed air of pollutant and by increasing the liquid trickling rate to $200 \mathrm{~mL} \mathrm{~min}^{-1}$. This simple procedure was done continuously for $4 \mathrm{~h}$, and repeated the next day, to remove the excess biomass accumulated on the surface of the monolith. The washed off biomass was then easily removed by sedimentation, and fresh nutrient media was added to replace the displaced volume. The pressure drop values were thus rapidly brought down again to the initial, negligible value of $0.1 \mathrm{~cm} \mathrm{H}_{2} \mathrm{O}$. Though, similar ILR were maintained after re-start, the RE did not improve significantly. This could be due to the fact that, some of the active biomass could have eventually sloughed off from the monolith surface during maintenance. As the original idea was to check for maximum EC at different EBRT, the concentration was further increased from 1.6 to $2.5 \mathrm{~g} \mathrm{~m}^{-3}$, corresponding to styrene loads as high as $115 \mathrm{~g} \mathrm{~m}^{-3} \mathrm{~h}^{-1}$ on the 55th day, where the RE 
decreased significantly to about $48 \%$. Apparently, an increase in the concentration in short maintenance period did not increase the biomass growth in the monolith reactor, which was also reflected by low pressure drop values during this period $\left(0.1 \mathrm{~cm} \mathrm{H}_{2} \mathrm{O}\right)$. This could be due to the toxicity effects caused by high styrene concentrations fed to the reactor after intermittent shutdown. In the next phase (days 56-92), the EBRT was reduced to $19 \mathrm{~s}$, and the concentrations were brought down to about $0.07 \mathrm{~g} \mathrm{~m}^{-3}$, from the previous value of $2.5 \mathrm{~g} \mathrm{~m}^{-3}$. Thus, at loading rates lesser than $20 \mathrm{~g} \mathrm{~m}^{-3} \mathrm{~h}^{-1}$, the RE was maintained at $100 \%$ for the next 9 days. The rapid decline of the RE values at high styrene loads and the subsequent restoration of $100 \% \mathrm{RE}$ at low styrene loads shows the fast response of the monolith reactor and the fungus, Sporothrix sp., to fluctuating concentration gradients within the bioreactor. This observation also confirms the sensitivity and restoration capability of the fungus. On the contrary, during this period, the pressure drop values started to slowly increase, giving sufficient evidence that new fungal spores were formed within the monolith channels. In BTFs, used for waste gas treatment, microorganisms are believed to play a major role by creating clogging mats or biofilms, at the solid-solid interfaces of the infiltrative areas of these systems. Clogging of fungal packed-bed bioreactor is often somewhat faster than in reactors where bacteria are dominant populations. For fungal bioreactors, clogging occurs as a result of excess biomass growth and fluffy biofilm formation, which is controlled by phosphate limitation in fungi.

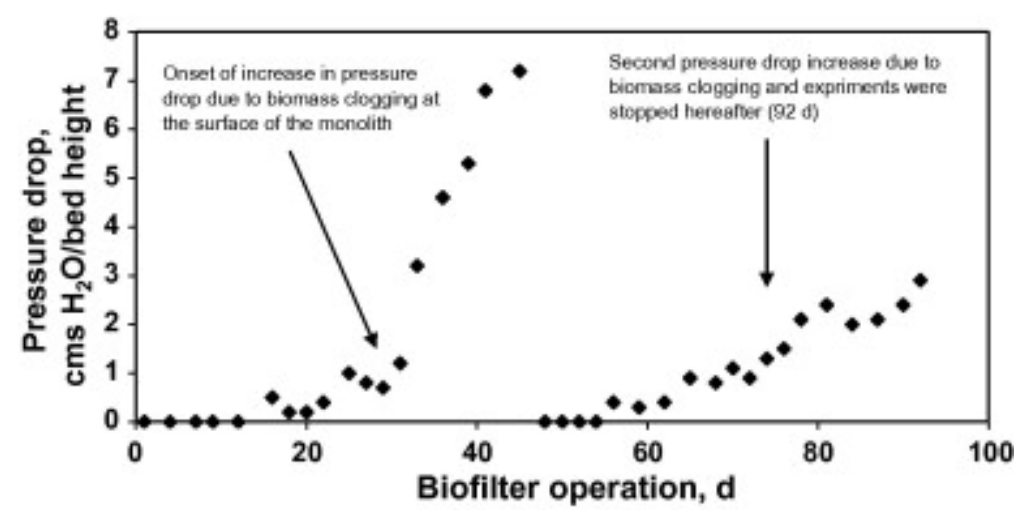

Fig. 3.

Profiles of pressure drop during monolith bioreactor operation.

\section{Figure options}

From the 71st day, the loading rates were increased in short time steps from $63.4 \mathrm{~g} \mathrm{~m}^{-3} \mathrm{~h}^{-1}$ to nearly $150 \mathrm{~g} \mathrm{~m}^{-3} \mathrm{~h}^{-1}$. During this operational period, the RE values were consistently less than $60 \%$ for loading rates greater than $70 \mathrm{~g} \mathrm{~m}^{-3} \mathrm{~h}^{-1}$ and the magnitude of this decrease was greater at higher loads. In biofilters, higher inlet loading rates have shown to result in strong inhibition of microbial activity, particularly severe at high air velocity (Kennes and Veiga, 2001 and Rene et al., 2009a). During this period, the pressure drop also increased to a maximum value of $2.9 \mathrm{~cm} \mathrm{H}_{2} \mathrm{O}$. Similar observations were also reported in our previous study with methanol in monolith bioreactor and it was postulated that regular washing, by temporarily increasing the flow rate of the trickling liquid, of the monolith will allow for a long-term, stable operation (Jin et al., 2008). 
Earlier, in this study, under normal trickling rate of the liquid, most of the liquid was concentrated in the central section of the monolith surface. However, when the incoming air was mixed with the trickling liquid before entry, some liquid still tends to concentrate in the central section of the monolith surface, though most of the liquid was distributed on the remaining leading ends of the monolith channels. Nevertheless, some minor portion of the liquid tend to splash and strike the wall surface in the mixing zone constantly, leading to some biomass growth on the wall surface (Fig. 1). This uneven liquid distribution also led to a much poorer biomass growth in the central part of the bioreactor compared to the rest of the monolith channels (ig. 1). This has not been an unusual observation in bioreactor configurations such as BF and BFs. However, it is proposed that maldistribution can be avoided by customizing the distributor. One possibility would be to re-design the distributor section by placing a bed of alumina or glass spheres and properly placing at the top of the monolith surface. This proposed modification at the entry section would allow the incoming liquid to break up into thin rivulets and spread across the cross-section of the alumina bed, and deliver in a free falling fashion on the monolith channels underneath. Besides, the distance separating the distributor and top surface has to be optimized, but this factor should be significant enough, so that the entire top surface of the monolith receives the liquid.

\subsection{Elimination capacity and $\mathrm{CO}_{2}$ generation profiles}

The degree of pollutant degrading capacity of a bioreactor is commonly quantified as a function of pollutant loading by determining the elimination capacity values. Also, EC is frequently used as a performance and design criterion for gas-phase biofilters. It is evident from Fig. 4 a, that the styrene elimination rate per unit packing volume of monolith increased linearly with an increase in the styrene inlet loading rate. At an EBRT of $77 \mathrm{~s}$, for ILR $<80 \mathrm{~g} \mathrm{~m}^{-3} \mathrm{~h}^{-1}$, nearly $90 \%$ of gas-phase styrene was removed by the attached Sporothrix sp. and converted to $\mathrm{CO}_{2}$. On the contrary, at an EBRT of $19 \mathrm{~s}$, the critical ILR to reach more than $90 \%$ RE was just about $40 \mathrm{~g} \mathrm{~m}^{-3} \mathrm{~h}^{-1}$. The results are not surprising, as the critical loads in biological waste gas treatment systems have shown to decrease with an increase in the gas-flow rate, i.e., decreasing EBRTs ( Kennes and Veiga, 2001 and Rene et al., 2009a). In our previous studies on styrene treatment in biofilters, it was observed that the maximum performance and critical load was highly dependant on the EBRT ( Rene et al., 2009b). Besides, it was observed that the maximum EC was a decreasing function of the gas-flow rate. At an EBRT of $77 \mathrm{~s}$, the maximum EC was $67.4 \mathrm{~g} \mathrm{~m}^{-3} \mathrm{~h}^{-1}$, while the EC was $55.9 \mathrm{~g} \mathrm{~m}^{-3} \mathrm{~h}^{-1}$ at an EBRT of $19 \mathrm{~s}$. Similar results have been reported in the literature for styrene treatment in biofilters. Jorio et al. (2000) observed maximum EC values of 49.5, 40.2, and $36.4 \mathrm{~g} \mathrm{~m}^{-3} \mathrm{~h}^{-1}$ at gas-flow rate of $0.5,0.7$, and $1 \mathrm{~m}^{-3} \mathrm{~h}^{-1}$, respectively, in a biofilter packed with pre-conditioned biomass and irrigated with aqueous solution of $\mathrm{KH}_{2} \mathrm{PO}_{4}$ and $\mathrm{KNO}_{3}$. Fig. 4b shows the influence of inlet concentration on the EC at different EBRTs tested in the monolith bioreactor. For a constant EBRT, as the styrene concentration increased, the maximum EC at first increased, reaching a maximum value corresponding to a given styrene concentration, and any further increase in this value led to a decrease in the EC values. These values are not the same for different EBRTs, i.e., concentrations yielding the maximum EC were 0.4 and $1.8 \mathrm{~g} \mathrm{~m}^{-3}$ for EBRTs of 19 and $77 \mathrm{~s}$. This range of styrene concentration $\left(0.4-1.8 \mathrm{~g} \mathrm{~m}^{-3}\right)$ can be considered as a safe operating regime, where the response of the monolith bioreactor to an increase in inlet concentration depends on the value of the EBRT. Jorio et al. (2000) suggested that 
identifying a safe range of concentration in biofilter is very crucial for long-term performance and can be very helpful in monitoring bioreactor's stability and operation.
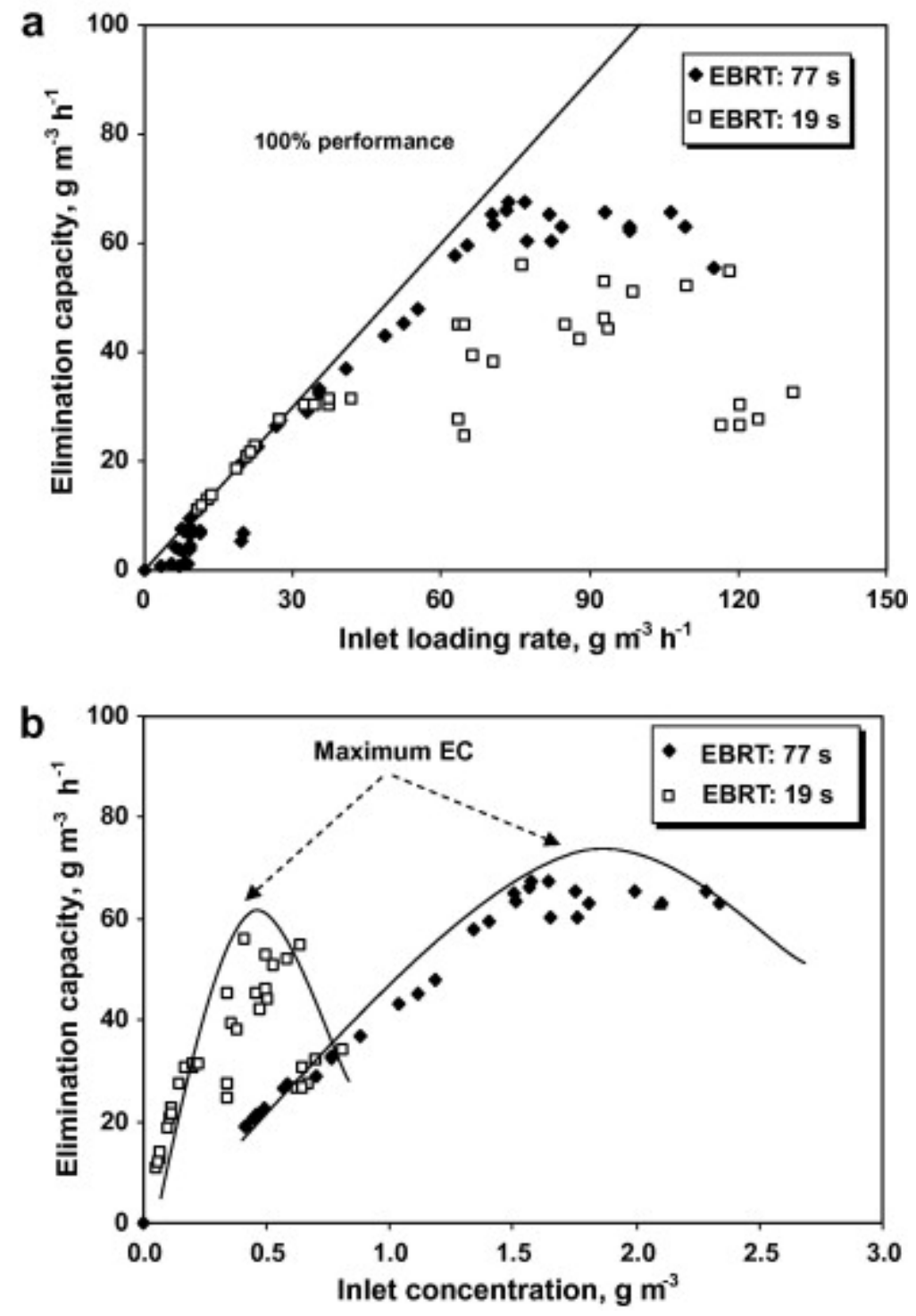

Fig. 4.

Effect of (a) styrene load and (b) inlet concentration on the elimination capacity of the monolith bioreactor.

\section{$\underline{\text { Figure options }}$}

In any biological waste gas treatment process, most volatile organic compounds are degraded to water, carbon dioxide, and biomass aerobically (Kennes et al., 2009). Hence it is important to monitor the profile of $\mathrm{CO}_{2}$ in the gas phase, at the inlet and outlet of the bioreactor, to acquire valuable information on the performance of the reactor and on the extent of mineralization of the pollutant. It was observed that the carbon dioxide generation rate $\left(\mathrm{P}_{\mathrm{CO} 2} \mathrm{PCO} 2\right)$ was a linear and increasing function of the observed elimination capacity (EC). For complete chemical oxidation of styrene to carbon dioxide and water, the ratio of carbon dioxide produced to styrene removed should be 3.4. The equation of the line was found to be, $y=2.7785 x \quad$ ( Fig. 5). Thus the slope of the line is approximately 2.8, indicating that this average ratio of 
$\mathrm{P}_{\mathrm{CO} 2} / \mathrm{ECPCO} / \mathrm{EC}$ is valid for all the test conditions, irrespective of the EBRTs. Though complete biodegradation of styrene could be confirmed through these results, the fraction of the unaccounted organic carbon consumed (17.6\%) could have been used for biomass production.

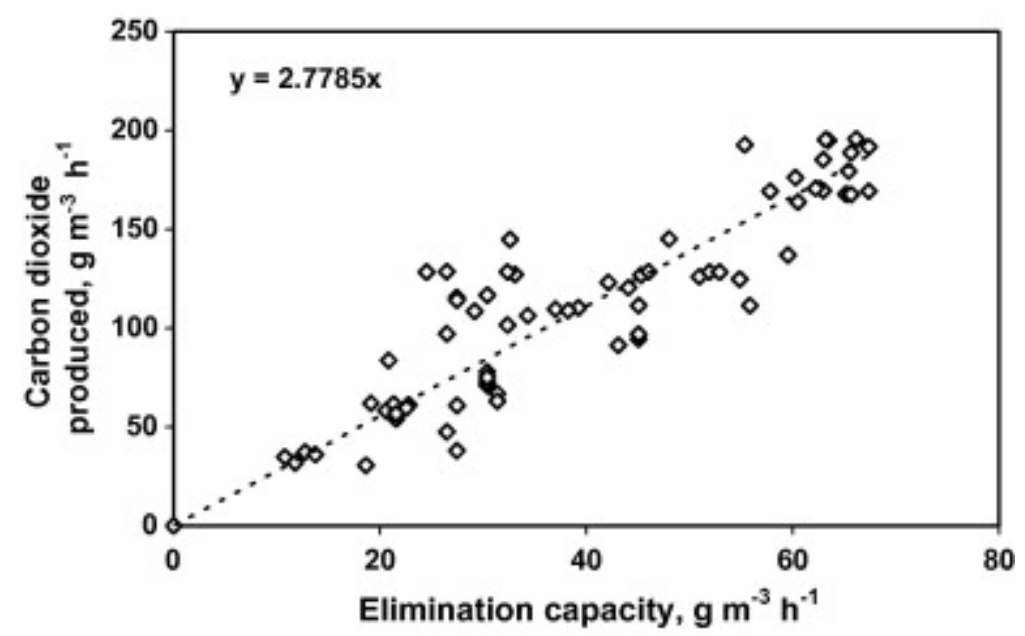

Fig. 5.

Carbon dioxide produced as a function of the styrene elimination capacity.

\section{Figure options}

A maximum styrene removal rate of $67.4 \mathrm{~g} \mathrm{~m}^{-3} \mathrm{~h}^{-1}$ was obtained at an inlet loading rate of $73.5 \mathrm{~g} \mathrm{~m}^{-3} \mathrm{~h}^{-1}$, and the RE was greater than $90 \%$. To our knowledge, this is the first report for styrene degradation in monolith bioreactor using Sporothrix sp., capable of degrading high concentrations of gas-phase styrene. A summarized literature overview on styrene removal was done to compare the EC of this study with different bioreactor configurations, such as BF and BTF, as shown in Table 1. In this table, we have used hypertext in the column 'inoculum' to link the footnotes that briefly describe the original source of inoculum and other literature cited in that context. Out of the 21 literature that was reviewed for this study, 62\% of the literatures have reported EC ranging from 11 to $100 \mathrm{~g} \mathrm{~m}^{-3} \mathrm{~h}^{-1}$, while only $10 \%$ have reported high ECs, $>600 \mathrm{~g} \mathrm{~m}^{-3} \mathrm{~h}^{-1}$. Kim et al. (2005) used a polyurethane foam biofilter inoculated with activated sludge and achieved EC ranging between 580 and $635 \mathrm{~g} \mathrm{~m}^{-3} \mathrm{~h}^{-1}$ at a space velocity (SV) of 50-200 $\mathrm{h}^{-1}$. The high elimination capacities achieved in their study was attributed to the presence of Pseudomonas sp., IS-5 and polyurethane foam packing material. Djeribi et al. (2005) studied the biofiltration of styrene in a lava rock packed BTF, in the presence of silicone oil, and reported EC as high as $3000 \mathrm{~g} \mathrm{~m}^{-3} \mathrm{~h}^{-1}$. However, without silicone oil, they observed roughly $18 \%$ decreases in the performance, and the high ECs were attributed to the presence of dominant styrenedegrading microorganisms that were later isolated. Though the results reported in our study fall under the 62\% range of literature reviewed for styrene removal, it is one step ahead from our previous work using monolith support for biofiltration, where a hydrophobic VOC in gas-phase (toluene) was removed successfully with a maximum EC of $30 \mathrm{~g} \mathrm{~m}^{-3} \mathrm{~h}^{-1}$ ( Jin et al., 2006a). A key issue that would allow reaching better results is the optimization of liquid supply in order to reach a much more homogenous biomass distribution, which was not the case in this study ( Fig. 1), and thus a better use of the full reactor volume. 
Table 1.

Literature review on styrene removal using different bioreactor configurations.

\begin{tabular}{|c|c|c|c|c|}
\hline \begin{tabular}{|l|} 
Sl \\
No. \\
\end{tabular} & Packing material & Inoculum & $\begin{array}{|lr|}\begin{array}{ll}\text { Max } & \text { EC } \\
\left(\mathrm{g} \mathrm{m}^{-3} h^{-1}\right)\end{array} \\
\end{array}$ & Reference \\
\hline 1 & Ceramic beads & \begin{tabular}{|l} 
Pseudomonas \\
putida, ST201 a
\end{tabular} & 90 & \begin{tabular}{|ll} 
Okamato et al. \\
$(2003)$
\end{tabular} \\
\hline 2 & Polyurethane foams & $\begin{array}{|ll|}\begin{array}{l}\text { Pseudomonas } \\
\text { IS-3 } \underline{\text { b }}\end{array} & \text { sp. } \\
\end{array}$ & 635 & $\begin{array}{lll}\text { Kim } & \text { et } & \text { al. } \\
(2005) & & \\
\end{array}$ \\
\hline 3 & Peat & 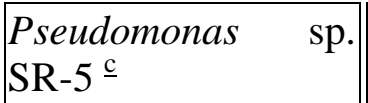 & 236 & \begin{tabular}{|lll} 
Jang & et & al. \\
$(2004)$ & &
\end{tabular} \\
\hline 4 & Ceramic & $\begin{array}{|ll|}\begin{array}{l}\text { Pseudomonas } \\
\text { SR-5 } \text { d }\end{array} & \text { sp. } \\
\end{array}$ & 81 & $\begin{array}{|lll|}\text { Jang } & \text { et } & \text { al. } \\
(2004) & & \\
\end{array}$ \\
\hline 5 & Perlite & \begin{tabular}{|l} 
Exophiala \\
jeanselmei
\end{tabular} & 91 & Cox et al. (1996) \\
\hline 6 & $\begin{array}{|ll|}\begin{array}{l}\text { Peat }+10 \% \\
\text { clay }+ \text { plastic }\end{array} & \text { burned } \\
\end{array}$ & Activated sludge $\mathrm{e}^{\mathrm{f}}$ & 30 & $\begin{array}{|lll|}\text { Arnold } & \text { et } & \text { al. } \\
(1997) & & \\
\end{array}$ \\
\hline 7 & Compost & Nocardia sp. ${ }^{\mathrm{g}}$ & 80 & Ottengraf (1986) \\
\hline 8 & Perlite & Mixed culture $\mathrm{e}^{\mathrm{h}}$ & 140 & $\begin{array}{|lll|}\text { Paca } & \text { et } & \text { al. } \\
(2009) & & \\
\end{array}$ \\
\hline 9 & $\begin{array}{l}\text { Yard } \\
\text { compost + shredded } \\
\text { plastics }\end{array}$ & $\begin{array}{l}\text { Thickened activated } \\
\text { sludge }\end{array}$ & 45 & \begin{tabular}{|l} 
Dehghanzadeh \\
et al. (2005)
\end{tabular} \\
\hline 10 & Perlite & \begin{tabular}{|l} 
Rhodococcus \\
pyridinovorans
\end{tabular} & 279 & $\begin{array}{l}\text { Jung and Park } \\
(2005)\end{array}$ \\
\hline 11 & $\begin{array}{l}\text { Pre-conditioned } \\
\text { biomass }\end{array}$ & \begin{tabular}{|l|} 
Activated \\
consortium \\
microbial species
\end{tabular} & 141 & \begin{tabular}{|lll} 
Jorio & et & al. \\
$(2000)$ & &
\end{tabular} \\
\hline 12 & \begin{tabular}{|l} 
Peat and ceramic \\
packing
\end{tabular} & $\begin{array}{|ll|}\begin{array}{l}\text { Pseudomonas } \\
\text { SR-5 c, } \underline{\text { S }}\end{array} & \text { sp. } \\
\end{array}$ & 86 & $\begin{array}{|lll|}\text { Jang } & \text { et } & \text { al. } \\
(2006) & & \\
\end{array}$ \\
\hline 13 & Perlite & Mixed culture $\mathrm{e}^{\mathrm{i}}$ & 384 & \begin{tabular}{|lll} 
Rene & et & al. \\
$(2009 a)$ & & \\
\end{tabular} \\
\hline 14 & \begin{tabular}{|l} 
Sterilized peat + glass \\
beads
\end{tabular} & $\begin{array}{|ll|}\begin{array}{l}\text { Rhodococcus } \\
\text { rhodochrous } \\
\text { NCIMB 13259 }\end{array} & \\
\end{array}$ & 50 & Zilli et al. (2001) \\
\hline 15 & \begin{tabular}{|l|}
$\begin{array}{l}\text { Polypropylene pall } \\
\text { rings }\end{array}$ \\
\end{tabular} & Mixed culture ${ }^{\mathrm{i}}$ & 11 & $\begin{array}{|lll|}\text { Novak } & \text { et } & \text { al. } \\
(2008) & & \\
\end{array}$ \\
\hline 16 & Celite pellets & Mixed culture $\mathrm{k}^{\underline{\mathrm{k}}}$ & 67 & $\begin{array}{|lll|}\text { Sorial } & \text { et } & \text { al. } \\
(1998) & & \\
\end{array}$ \\
\hline 17 & Lava stones & 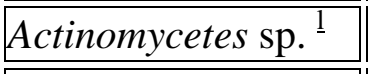 & 32 & Pol et al. (1998) \\
\hline 18 & Coal particles & Activated sludge $^{\underline{m}}$ & 44 & Lu et al. (2001) \\
\hline
\end{tabular}




\begin{tabular}{|c|c|c|c|c|}
\hline \begin{tabular}{|l|} 
Sl \\
No. \\
\end{tabular} & Packing material & Inoculum & \begin{tabular}{|lr}
$\operatorname{Max}$ & $\mathrm{EC}$ \\
$\left(\mathrm{g} \mathrm{m}^{-3} \mathbf{h}^{-1}\right)$
\end{tabular} & Reference \\
\hline \multirow{2}{*}{19} & \multirow{2}{*}{ Lava stones } & \multirow{2}{*}{ Mixed culture ${ }^{\underline{n}}$} & $3000^{0}$ & Djeribi et al. \\
\hline & & & $2500^{\mathrm{p}}$ & $(2005)$ \\
\hline 20 & Polyurethane foams & Brevibacillus sp. & 125 & \begin{tabular}{|lll} 
Hwang & et & al. \\
$(2008)$ & & \\
\end{tabular} \\
\hline 21 & Blast furnace slag & Activated sludge & 30 & \begin{tabular}{|l|} 
Chou and Hsiao \\
$1998)$ \\
\end{tabular} \\
\hline 22 & Monolith support & \begin{tabular}{|l} 
Sporothrix \\
variecibatus
\end{tabular} & 67 & - This study - \\
\hline
\end{tabular}

Notes: Sl No. 1-14: BF.

Sl No. 15-21: BTF.

Sl No. 22: Monolith reactor.

a Enriched from soil samples collected from the site of synthetic rubber factory.

b Enriched from activated sludge from a wastewater treatment plant.

c,d Several soils and sludge as inoculum (non-defined).

e Isolated from a previously operated biofilter containing mixed populations of fungi (Cox, 1995).

f Enriched originally from activated sludge, later, seven different bacterial isolates belonging to genera Tsukamurella, Pseudomonas, Sphingomonas, Xanthomonas and an unidentified genus in the $\gamma$ group of the Proteobacteria were isolated.

g Enriched from activated sludge.

$\mathrm{h}$ Microbial analysis from different stages of biofilter confirmed the presence of eukaryotic strains (Aspergillus oryzae and Penicillium sp.,) and Pseudomonads (Pseudomonas aeruginosa and two groups of gram-negative bacteria).

i Obtained from wastewater treatment plant sludge of a petrochemical industry and the most dominant fungus, a Sporothrix sp., was isolated.

$\mathrm{j}$ Inoculum taken from a previously running styrene-degrading biofilter.

$\mathrm{k}$ Microbial seed from decanted water obtained from cleaning pellets used in a previously operating biofilter treating toluene.

l Enriched from various soil samples and activated sludge as inoculum.

m Obtained from a secondary clarifier of a waste water treatment plant.

n Mixed culture was obtained from a CSTR fed with styrene in a two-phase system. Four different strains were isolated and identified as Pseudomonas putida (C1), Achromobacter sp., (C2), Achromobacter sp., (C3), and Pseudomonas aeruginosa (C4).

o With oil.

p Without oil. 


\subsection{Effect of shock loads}

Since biological waste gas systems include the presence of active microorganisms, they are sensitive to sudden variations of flow rate or concentration or a combination of both at once, i.e., load fluctuations. It has been understood clearly in bioreactor configurations like BF, BTF and CSTB, that microorganisms could sustain sudden, yet medium shock loads well. High shock loads are harder to tolerate over a long period of time, especially for hydrophobic VOCs (Rene et al., 2005 and Rene et al., 2009a). A short exposure to high pollutant concentrations could easily inhibit or even kill the microorganisms, which is quite possible in certain chemical sectors, where process units are relatively small and operated in batch mode, leading to large variations in effluent concentrations. Hence, due to the variable nature of waste gases from process industries, it is essential to test reactor stability to shock loading conditions, as a precautionary factor, which would be of great importance during the design step of any biological treatment system.

Some decrease in the performance of fungal systems should be expected in response to continuous dynamic loads. However, our experience with transient loads indicates that fungal biofiltration is generally quite resistant and can tolerate fluctuations in inlet loading rates comfortably for hydrophobic VOCs, like $\alpha$-pinene (Jin et al., 2006b). The objective of our study was therefore to simulate loading fluctuations and observe the response in the laboratory scale monolith bioreactor. For this purpose, two experiments were planned. The first one, a $6 \mathrm{~h}$ short-term overload study at an EBRT of $77 \mathrm{~s}$, giving rise to medium shock loads, and the second one, a moderately long-term - $36 \mathrm{~h}$ study at an EBRT of $19 \mathrm{~s}$, with high shock loads, at loading rates that were not earlier tested under regular experiments.

The results shown in Fig. 6a and b, indicate that the styrene laden monolith bioreactor was sensitive to fluctuations in loading rates. A sudden increase in the ILR from 10 to $85 \mathrm{~g} \mathrm{~m}^{-3} \mathrm{~h}^{-1}$ decreased the RE from nearly 100-61\% during medium shock loads (EBRT - 77 s). During this phase of shock load, the EC increased from an original low value of $10-55 \mathrm{~g} \mathrm{~m}^{-3} \mathrm{~h}^{-1}$ and then remained almost constant during the $6 \mathrm{~h}$ medium shock load. When the ILR was reduced and brought back to original values, the EC decreased, leading to a restoration of the RE (100\%). However, when a high shock load was applied (56-186 $\mathrm{g} \mathrm{m}^{-3} \mathrm{~h}^{-1}$ ) at an EBRT of $19 \mathrm{~s}$, the removal efficiency dropped suddenly, to nearly $30 \%$ and then remained almost constant at such value during the shock load period of $36 \mathrm{~h}$. However, the EC remained basically unchanged during the shock load compared to its value before the shock load. In both these shock loads, the response of the monolith bioreactor was fast as seen from the immediate decrease in removal profile at high loads, and, when pre-shock steady-state conditions were restored, the recovery time of the fungus-inoculated monolith bioreactor to achieve original performance was almost instantaneous $(<1 \mathrm{~h})$. The monolith bioreactor showed good resistance to increase in loading conditions, and it was observed that, irrespective of the shock load variations due to changes in both concentration and EBRT, the maximum EC value varied between 50 and $55 \mathrm{~g} \mathrm{~m}^{-3} \mathrm{~h}^{-1}$. These values, however, are comparable to the maximum EC (67.4 and $56 \mathrm{~g} \mathrm{~m}^{-3} \mathrm{~h}^{-1}$ at an EBRT of 77 and $19 \mathrm{~s}$ ) achieved under normal loading conditions (Fig. 4a). Two different phenomena were observed during these shock loads. In the short-term shock load, an increase in the ILR from 10 to $85 \mathrm{~g} \mathrm{~m}^{-3} \mathrm{~h}^{-1}$ caused an increase in the EC from nearly 10 to $55 \mathrm{~g} \mathrm{~m}^{-3} \mathrm{~h}^{-1}$, while in the second long-term shock load study, an increase in the load from 56 to 
$186 \mathrm{~g} \mathrm{~m}^{-3} \mathrm{~h}^{-1}$ did not significantly affect the EC, and this value remained almost constant (50-55 $\mathrm{g} \mathrm{m}^{-3} \mathrm{~h}^{-1}$ ). The monolith bioreactor operated here, in the former case was limited by biological reaction, while in the later, mass transfer was limiting the EC, a contaminant transport problem often encountered in BTF, when treating more hydrophobic VOCs like styrene. The results from this study show that the system is quite resistant to high shock loads, where the EC remains almost constant, though there is a significant drop in the RE. Besides, this system is rather robust as it quickly achieves optimal conditions after the shock load.
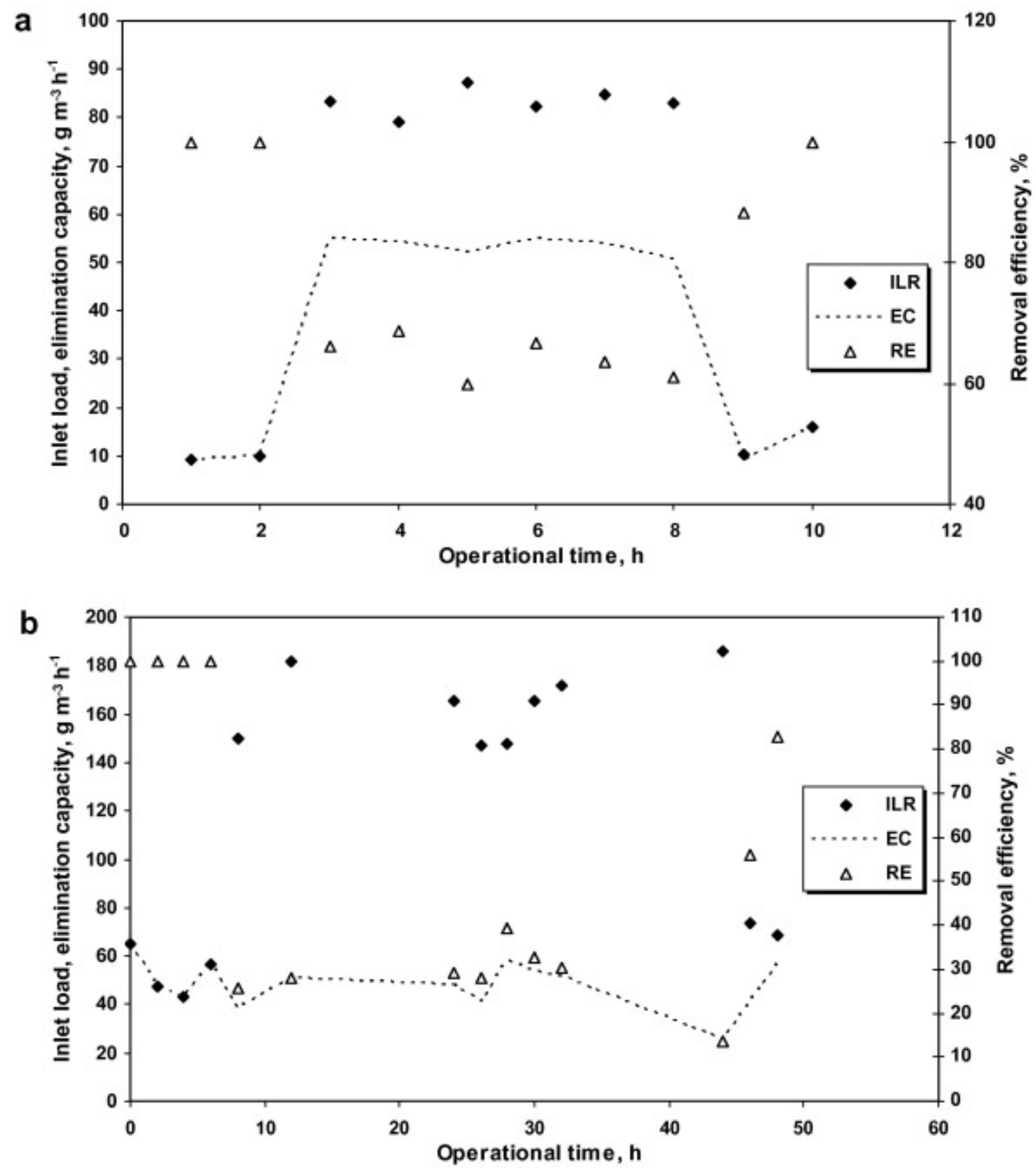

Fig. 6.

Performance of monolith bioreactor during (a) short-term (low-medium loading) and (b) long-term (low-high loading) shock loads. 


\section{Conclusions}

The removal of gas-phase styrene in the monolith bioreactor decreased with an increase in inlet concentration and gas-flow rate. The elimination capacity profiles at constant gas-flow rates, increased with increase in styrene concentration, up to a maximum and then decreased when the concentration was increased. There are certain critical factors that have to be addressed and satisfied before implementing monolith bioreactors for full-scale applications. A proper liquid distribution system at the top would ensure homogenous biomass distribution, while problems with biomass clogging can be easily solved by increasing the flow rate of the trickling nutrient phase.

\section{Acknowledgements}

The present research was financed by the Spanish Ministry of Science and Innovation (Project: CTM2007-62700/TECNO), and through European FEDER funds. Eldon R. Rene thanks the Ministry of Science and Innovation for his "Juan de La Cierva" - post doctoral research contract. The Ph.D. research work of M. Estefania López is partly being supported by the Environmental Engineering Group of the University of La Coruńa, Spain.

\section{References}

M. Arnold, A. Reittu, A. von Wright, P.J. Martikainen, M.L. Suihko

Bacterial degradation of styrene in waste gases using peat filter

Appl. Microbiol. Biotechnol., 48 (1997), pp. 738-744

M.S. Chou, C.C. Hsiao

Treatment of styrene-contaminated airstream in biotrickling filter packed with slags

ASCE J. Environ. Eng., 124 (1998), pp. 844-850

H.H.J. Cox, B.W. Faber, W.N.M. van Heiningen, H. Radhoe, H.J. Doddema, W. Harder Styrene metabolism in Exophiala jeanselmei and involvement of a cytochrome P-450dependent styrene monooxygenase

Appl. Environ. Microbiol., 62 (1996), pp. 1471-1474

R. Dehghanzadeh, A. Torkian, B. Bina, H. Poormoghaddas, A. Kalantary

Biodegradation of styrene laden waste gas stream using a compost-based biofilter

Chemosphere, 60 (2005), pp. 434-439

R. Djeribi, T. Dezenclos, A. Pauss, J. Lebeault

Removal of styrene from waste gas using a biological trickling filter

Eng. Life Sci., 5 (2005), pp. 450-457

E. Estévez, M.C. Veiga, C. Kennes

Biofiltration of waste gases with the fungi Exophiala oligosperma and Paecilomyces variotii 
Appl. Microbiol. Biotechnol., 67 (2005), pp. 563-568

Y. Fang, R. Govind

A "convective" flow biofilter for the biofiltration of contaminants at sub-low concentrations

Remediation, 18 (2007), pp. 95-107

J.W. Hwang, C.Y. Choi, S.-H. Park, E.-Y. Lee

Biodegradation of gaseous styrene by Brevibacillus sp. using a novel agitating biotrickling filter

James, D.H., Castor, W.M., 2000. Styrene. In: Ullmann’s Encyclopedia of Industrial Chemistry, vol. A25, p. 329.

J.H. Jang, M. Hirai, M. Shoda

Styrene degradation by Pseudomonas sp. SR-5 in biofilters with organic and inorganic packing materials

Appl. Microbiol. Biotechnol., 65 (2004), pp. 349-355

J.H. Jang, M. Hirai, M. Shoda

Effect of shutdown on styrene removal in a biofilter inoculated with Pseudomonas sp. SR-5

J. Hazard. Mater., B129 (2006), pp. 223-227

Y. Jin, M.C. Veiga, C. Kennes

Development of a novel monolith bioreactor for the treatment of VOC-polluted air

Environ. Technol., 27 (2006), pp. 1271-1277

Y. Jin, M.C. Veiga, C. Kennes

Performance optimization of the fungal biodegradation of $\alpha$-pinene in gas-phase biofilter

Proc. Biochem., 41 (2006), pp. 1722-1728

Y. Jin, M.C. Veiga, C. Kennes

Removal of methanol from air in a low-pH trickling monolith bioreactor

Proc. Biochem., 43 (2008), pp. 925-931

H. Jorio, L. Bibeau, M. Heitz

Biofiltration of air contaminated by styrene: effect of nitrogen supply, gas flow rate and inlet concentration

Environ. Sci. Technol., 34 (2000), pp. 1764-1771

I.G. Jung, C.H. Park

Characteristics of styrene degradation by Rhodococcus pyridinovorans isolated from a biofilter

Chemosphere, 61 (2005), pp. 451-456

C. Kennes, H.H.J. Cox, H.J. Doddema, W. Harder

Design and performance of biofilters for the removal of alkylbenzene vapours 
J. Chem. Technol. Biotechnol., 66 (1996), pp. 300-304

C. Kennes, F. Thalasso

Waste gas biotreatment technology

J. Chem. Technol. Biotechnol., 72 (1998), pp. 303-319

C. Kennes, M.C. Veiga

Bioreactors for Waste Gas Treatment

Kluwer Academic Publishers, Dordrecht, Boston (2001)

C. Kennes, M.C. Veiga

Fungal biocatalysts in the biofiltration of VOC polluted air

J. Biotechnol., 113 (2004), pp. 305-319

C. Kennes, E.R. Rene, M.C. Veiga

Bioprocesses for air pollution control

J. Chem. Technol. Biotechnol., 84 (2009), pp. 1419-1436

J. Kim, H.W. Ryu, D.J. Jung, T.H. Lee, K.-S. Cho

Styrene degradation in a polyurethane biofilter inoculated with Pseudomonas sp. IS-3

J. Microbiol. Biotechnol., 15 (2005), pp. 1207-1213

M.T. Kreutzer, F. Kapteijn, J.A. Moulijn, J.J. Heiszwolf

Multiphase monolith reactors: Chemical reaction engineering of segmented flow in microchannels

Chem. Eng. Sci., 60 (2005), pp. 5895-5916

C.S. Lu, M.R. Lin, I.H. Wey

Removal of pentane and styrene mixtures from waste gases by a trickle-bed air biofilter

J. Chem. Technol. Biotechnol., 76 (2001), pp. 820-826

V. Novak, M. Halecky, K. Jones, H. Schmauder, C. Soccol, J. Paca

Styrene biofiltration in a trickle bed bioreactor

Braz. Arch. Biol. Technol., 51 (2008), pp. 385-390

Okamoto et al., 2003

K. Okamoto, M. Izawa, H. Yanase

Isolation and application of a styrene-degrading strain of Pseudomonas putida to biofiltration

J. Biosci. Bioeng., 95 (2003), pp. 633-636

S.P.P. Ottengraf

Exhaust gas purification

H.-J. Rehm, G. Reed (Eds.), Biotechnology, vol. 8VCH Verlagsgesellschaft, Weinheim, FRG (1986), pp. 425-452

J. Paca, M. Halecky, E. Kozliak

Styrene biofiltration using two packing materials with different adsorption properties Environ. Eng. Sci., 26 (2009), pp. 195-208 
A. Pol, F.J.J. van Haren, H.J.M. Op den Camp, C. van der Drift Styrene removal from waste gas with a bacterial biotrickling filter Biotechnol. Lett., 20 (1998), pp. 407-410

E.R. Rene, D.V.S. Murthy, T. Swaminathan

Performance evaluation of a compost biofilter treating toluene vapours

Proc. Biochem., 40 (2005), pp. 2771-2779

E.R. Rene, M.C. Veiga, C. Kennes

Performance of a biofilter for the removal of high concentrations of styrene under steady and non-steady state conditions

J. Hazard. Mater., 168 (2009), pp. 282-290

E.R. Rene, M.C. Veiga, C. Kennes

Experimental and neural model analysis of styrene removal from polluted air in a biofilter

J. Chem. Technol. Biotechnol., 87 (2009), pp. 941-948

G.A. Sorial, F.L. Smith, M.T. Suidan, A. Pandit, P. Biswas, R.C. Brenner Evaluation of trickle-bed air biofilter performance for styrene removal Water Res., 32 (1998), pp. 1593-1603

J.R. Woertz, K.A. Kinney, N.D.F. McIntosh, P.J. Szaniszlo

Removal of toluene in a vapour-phase bioreactor containing a strain of the dimorphic black yeast Exophiala lecanii-corni

Biotechnol. Bioeng., 75 (2001), pp. 550-558

M. Zilli, E. Palazzi, L. Sene, A. Converti, M. Del Borghi

Toluene and styrene removal from air in biofilters

Proc. Biochem., 37 (2001), pp. 423-429 